\title{
Tariff Evasion and Customs Corruption: Does Pre-Shipment Inspection Help?*
}

\author{
José Anson ${ }^{\dagger}$ \\ Olivier Cadot ${ }^{\ddagger}$ \\ Marcelo Olarreaga $a^{\S}$
}

\begin{abstract}
This paper provides a new approach to the evaluation of pre-shipment inspection (PSI) programs as ways of improving tariff-revenue collection and reducing fraud when customs administrations are corrupt. We build a model highlighting the contribution of surveillance firms to the generation of information and describing how incentives for fraud and collusive behaviour between importers and customs are affected by the introduction of PSI. It is shown theoretically that the introduction of PSI has an ambiguous effect on the level of customs fraud. Empirically, our econometric results suggest that PSI reduced fraud in the Philippines; it increased it in Argentina and had not significant impact in Indonesia.
\end{abstract}

JEL classification numbers: F10, F11, F13

Keywords: Trade, Tariff Revenue, Corruption, Pre Shipment Inspection.

${ }^{*}$ This research was produced as part of a World Bank research program on Customs corruption and Pre-Shipment Inpsection services. We are grateful to Nigel Balchin, Caroline Freund, Fred Herren, Francis Ng, Alessandro Nicita, Jerzy Rozanski, Maurice Schiff, Shang-Shin Wei, Luc De Wulf and participants at seminars at the Troisieme Cycle Romand in Crans-Montana and the World Bank for very helpful comments and suggestions. We retain however sole responsibility for any remaining error. The views expressed here are those of the authors and should not be attributed to the institutions to which they are affiliated.

†HEC Lausanne; e-mail: jose.anson@hec.unil.ch.

${ }^{\ddagger}$ HEC Lausanne, CERDI and CEPR; olivier.cadot@hec.unil.ch.

${ }^{\S}$ World Bank and CEPR; molarreaga@worldbank.org 


\section{Non-Technical Summary}

First introduced in Zaire in 1963 and adopted since then by over fifty countries worldwide, Pre-Shipment Inspection (PSI) consists of requiring imports to be inspected by a private surveillance company at embarkation ports or airports or in the exporter firms' premises, instead of just at the importing country's customs. Originally, PSI was intended to fight the use of overinvoiced imports to evade capital controls. As capital controls were progressively phased out, the attention of governments shifted to import-tariff evasion and, starting with Indonesia's program in 1985, the mission assigned to PSI accordingly changed to curbing underinvoicing.

The objective of this paper is to provide a new approach to the evaluation of PSI programs as ways of reducing customs fraud. After providing some inconclusive prima facie evidence for sixteen developing countries for which we had trade data before and after the introduction of PSI services, we adopt a more structural approach. We first set up a simple game-theoretic model of tariff evasion and customs effort generating testable predictions about the relationship between tariff rates and evasion. The model relies on an information-production framework developed by Aghion and Tirole (1997) and applied to corruption problems by Anson (2003). The idea is essentially that customs must spend costly resources assessing the value of shipments and that the outcome of their effort is stochastic (that is, higher levels of effort only reduce the likelihood of errors). This idea seems particularly well suited to a customs-operation context where officers must determine how thoroughly they inspect shipments knowing that exact valuation may be elusive even after careful inspection (especially for capital equipment which requires technical knowledge to be properly valued). In this context, what PSI does is to provide additional information on shipment value. In a perfect world, this information would only be used by the client government to control fraud. But this additional information is now available to a potentially corrupt customs officers which can use it to extract higher rents from importers through bribery arrangements, leading to higher customs fraud.

Thus, whether PSI increases or reduces customs fraud becomes an empirical question. We tested our structural model on panels of disaggregated trade data for three developing countries that have used PSI services (Argentina, Philippines and Indonesia). Our estimates suggest that customs fraud increased in Argentina after the introduction of PSI services, it was reduced in the Philippines and there was no impact in the case of Indonesia. 


\section{Introduction}

First introduced in Zaire in 1963 and adopted since then by over fifty countries worldwide, Pre-Shipment Inspection (PSI) consists of requiring imports to be inspected by a private surveillance company ${ }^{1}$ at embarkation ports or airports or in the exporter firms' premises, instead of just at the importing country's customs. Originally, PSI was intended to fight the use of overinvoiced imports to evade capital controls. As capital controls were progressively phased out, the attention of governments shifted to import-tariff evasion and, starting with Indonesia's program in 1985, the mission assigned to PSI accordingly changed to curbing underinvoicing.

Whether they look for over- or underinvoiced imports, surveillance companies are entrusted by client governments with the assessment of an important tax base and become, de facto, quasi tax collectors, even if tariff collection remains de jure under state authority. Although private tax collection is, by itself, an old practice, ${ }^{2}$ outsourcing such a key state function to the private sector can nonetheless be perceived by governments as a major delegation of authority, compounded by a sense of loss of sovereignty if those companies are foreign ones. To be politically acceptable, thus, PSI needs to be justified by strong arguments (for a brief review of those arguments, see Ramirez, 1992 or Byrne, 1995; on the difficulties encountered by the WTO Agreement on Customs Valuation in developing countries, see Goorman and

\footnotetext{
${ }^{1}$ The market is dominated by a small number of companies: Geneva-based Société Générale de Surveillance (SGS) and Cotecna, Paris-based Bureau Veritas, London-Based Inchcape Testing Services International (ITSI), and Houston-based Inspectorate America.

2 "Tax farming", consisting of trusting tax collection to private individuals allowed to retain a percentage of tax revenue, was widespread among Europe's monarchies up to the XVIIIth century. On this, see e.g. Stella (1993).
} 
De Wulf, 2003).

In the absence of PSI, customs operations in developing countries have been plagued by two problems. First, when collusive corruption between customs administrations and importers is widespread (as it is in many of the least developed countries), underinvoicing is neither reported nor corrected, depriving cash-constrained governments of much-needed tax revenue. Second, inefficient customs operations - long clearance times and complicated procedures - act as dissipative trade barriers, i.e. barriers that raise the cost of imports without generating revenue. Corruption and inefficiency are often two faces of the same coin as customs officers deliberately obstruct procedures in order to force traders to pay bribes. These are very serious issues which help explain why countries having reformed their trade regime but not their customs administration have sometimes failed to reap the full benefits of trade liberalization. Faced with a lack of political will to implement effective customs reforms, the World Bank and other donor institutions have sometimes recommended the outsourcing of customs operations to the private sector with the objective of providing a parallel information system that enables the government to control the tax collection functions of its own burocracy (see Low, 1995).

Has PSI really helped mitigating the problems that prompted its use? To our knowledge, there have been to date only two attempts at measuring in a systematic way PSI's impact on collected tariff revenue. First, a report by Argentina's Latin American Economic Research Foundation, commissioned in 1999 by SGS (FIEL 1999), compared the unit values of imports into Argentina with unit values of similar goods destined to Chile. On the 
assumption that Chilean customs are by and large uncorrupt, the discrepancy between unit values was taken as a proxy for underinvoicing of shipments to Argentina. FIEL found indeed that underinvoicing was curbed by the introduction of PSI. One problem with FIEL's methodology is that the introduction of PSI services may have been accompanied with other tariff and/or customs reforms. ${ }^{3}$ Moreover, even if we fully attribute the decline in underinvoicing to the introduction of PSI services, one may wonder whether this decline was sufficiently large to compensate for the budgetary cost of PSI (typically around one percent of imports; see next section).

More recently, Yang (2002) assessed the performance of the Philippines' PSI program, taking advantage of its staggered implementation. As a progressively larger number of source countries were included, he showed that imports covered by the program were increasingly diverted to tax-exempt export processing zones, and from there illegally brought onto the domestic market. ${ }^{4}$ Thus, in the presence of tax loopholes, PSI seemed to have affected the form of fraud rather than its extent. Yang's results for the Philippines were reinforced by panel estimation of a measure of underinvoicing (discussed below) on tariff rates and a dummy variable equal to one for country/year pairs with PSI programs in force. The PSI dummy was insignificant, suggesting no statistically traceable effect of PSI on collected tariff revenue.

By its very nature, like all forms of fraud, tariff evasion cannot be measured directly, so roundabout methods must be used. The most common one

\footnotetext{
${ }^{3}$ Some have argued that a more uniform tariff structure may reduce tariff evasion; see Gatti, 1999.

${ }^{4}$ Yang explains why such trade deflection did not take place before the program's introduction by arguing that if PSI raises the variable cost of fraud while deflection to the EPZ involves a fixed cost, PSI can make deflection attractive when it was not before.
} 
consists of comparing the records of source and destination customs. Traders attempting to evade import tariffs will underinvoice the value of shipments to destination customs while no such incentive exists at origin ones. In the presence of import-tariff evasion, discrepancies between source and destination trade data reported to Comtrade by national customs will thus reflect not just CIF/FOB differences and measurement errors (on this, see De Wulf, 1981, or Feenstra and Hanson, 2000) but also the extent of deliberate underinvoicing.

There are several potential problems with this method. One is that for the very reason that they are primarily interested in collecting tariffs and verifying compliance with domestic regulations, customs monitor imports more carefully than (if at all) exports. Thus, exports are subject to significant measurement errors. However, exporters are legally liable for their declarations to customs. If, upon audit by their home country's fiscal authorities (say, for corporate profits tax verification), they were shown to have double accounts, they would be in breach of tax laws. One may suppose that they will avoid putting themselves in such a situation without a good reason to do so.

Another problem is that, until all governments adopt the WTO's "transaction value" principle, idiosyncratic regulations may bias customs-recorded values. For instance, until 1996 the Philippino government enforced a Home Consumption Value (HCV) rule according to which imports into the Philippines had to be valued at the exporting country's first-level-of-distribution price. Thus, goods imported from, say, Switzerland and sold in the Philippines at a fraction of their Swiss price had nevertheless to be reported at 
their Swiss ex-factory price instead of at the transaction's actual price. The HCV rule biased downward the degree of underinvoicing apparent in trade statistics. ${ }^{5}$ None of these issues is serious enough to jettison the comparisonof-trade-values method, but they suggest that care must be exercised in its use.

Based on this method Fisman and Wei (2001) found that import-tariff evasion between Hong-Kong and mainland China is significant, both through underinvoicing and through (presumably deliberate) misclassification of imports into tariff lines with lower rates. They also found a positive relationship between tariff rates and underinvoicing.

If the idea that higher tariffs encourage fraud sounds plausible a priori, the relationship may not, as a matter of fact, be so clear-cut. For instance, categories of goods with high tariffs may be those most carefully scrutinized by customs, so trying to fraud in those categories may be just the wrong thing to do. Indeed, the relationship between tax rates and tax evasion can theoretically go either way (see Slemrod and Yitshaki, 2000, for a survey).

In this paper, we first provide prima-facie evidence on the impact of PSI on tariff evasion in different countries using nonparametric methods. For each country and year, we derive kernel densities of the degree of underinvoicing across tariff lines. We then retrieve cumulative distribution functions (CDF) and propose a simple test: when the pre-PSI CDF of the underinvoicing variable dominates the post-PSI one in the first order, PSI can be said to have reduced underinvoicing.

\footnotetext{
${ }^{5}$ We are grateful to the SGS for providing this information. On this, see also Medalla et al. $(1993,1999)$.
} 
Second, we set up a simple game-theoretic model of tariff evasion and customs effort generating testable predictions about the relationship between tariff rates and evasion. The model relies on an information-production framework developed by Aghion and Tirole (1997) and applied to corruption problems by Anson (2003). The idea is essentially that customs must spend costly resources assessing the value of shipments and that the outcome of their effort is stochastic (that is, higher levels of effort only reduce the likelihood of errors). This idea seems particularly well suited to a customsoperation context where officers must determine how thoroughly they inspect shipments knowing that exact valuation may be elusive even after careful inspection (especially for capital equipment which requires technical knowledge to be properly valued). In this context, what PSI does is to provide additional information on shipment value. In a perfect world, this information would only be used by the client government to control fraud. Alternatively, if government authorities fail to use the information through audits and reconciliation, it simply generates informational rents for corrupt customs officer that they will share with importers through bribery arrangements.

Thus, with endogenous customs effort, importers deciding how much they underinvoice must avoid attracting customs' curiosity, not so much because of penalty tariffs but because uncovered fraud improves the bargaining position of corrupt customs officers. The model shows that the introduction of PSI services has an ambiguous impact on the extent of customs fraud. The model also shows that irrespective of the presence of PSI, there tends to be less underinvoicing in product categories with high tariff rates because those are subject to more careful inspection and importers know it. 
We test this prediction by structural estimation of the model's first-order condition on panels of disaggregated imports for several countries and years and find that indeed, underinvoicing is inversely related to tariff rates. Our estimates also suggest that the extent of fraud might increase or decrease after PSI's introduction.

The paper is organized as follows. Section 2 briefly describes PSI procedures. Section 3 presents nonparametric test results for a sample of countries. Section 4 sets out the model, and section 5 presents the econometric analysis and results. Section 6 concludes.

\section{PSI procedures}

Import procedures under PSI vary, but the typical one is roughly as follows. ${ }^{6}$ The trader operating in the port of shipment must first provide the PSI company's local agent with a detailed description of the shipment, which is then inspected. Upon inspection, the PSI company issues a Report of Findings, which falls into two categories: a Clean Report of Finding (CRF), when the PSI company confirms the trader's declaration or a Discrepancy Report (DR) when the PSI uplifts the value declared by the trader. The CRF or DR serves as a basis for the determination of applicable importtax regime (tariff line, special regimes, exemptions etc...) and is sent to the destination port's customs and PSI company agent. In addition, it is also sent for reconciliation purposes to the client government's Ministry of Finance; the extent of reconciliation between customs data and the CRF/DR by the

\footnotetext{
${ }^{6}$ For a more detailed description, see Low (1995), page 9.
} 
Ministry of Finance varies across countries, but the reconciliation rates tend to be low.

At the destination port, the importer or a registered commissioner forwards one copy of the report to the appropriate customs office, together with a set of official customs documents on the basis of which duties payable are assessed. On the basis of these two sets of documents (CRF/DR and customs documents) the PSI company calculates all taxes and duties, which are paid by the importer or commissioner to a designated bank account, from which they are transferred to the Customs' account at the Central Bank and then finally to the Treasury. To these duties, the PSI company adds a fee paid by the importer, typically about $1 \%$ with a minimum amount. ${ }^{7}$ Shipments landing at the port of destination without having been inspected at the port of embarkation are liable to destination inspection, with penalties for repeat offenses (typically, additional taxes on the second occurrence and seizure thereafter). Customs also sometimes perform independent inspections (in addition to PSI).

Disputes between importers and the PSI companies should in principle be settled by an arbitration body, but few PSI-using countries have set up such bodies. In their absence, importers have no recourse in case of dispute with the PSI company beyond the right to a second inspection, usually performed in the 48 hours following the complaint.

\footnotetext{
${ }^{7}$ For instance, in a number of countries, SGS charges $1.05 \%$ of shipment value over a de minimis threshold of $\$ 5,000$ with a minimum fee of SFr 450 (around $\$ 300$ ). For small shipments, this may add substantially to the burden of import tariffs (a $\$ 300$ fee on a $\$ 5,000$ shipment represents an ad-valorem equivalent of $6.15 \%$ ) and this may have non-negligeable effects in LDCs (least developed countries) where median shipment size is small. See WTO (1999).
} 


\section{PSI and underinvoicing: prima-facie evi- dence}

This section provides evidence on tariff evasion before and after the introduction of PSI services for a subsample of 16 countries, for which trade data was available during a sufficient number of periods preceding and following the introduction of PSI, among a set of 52 countries that have used PSI services at some point in time. ${ }^{8}$ The method used here is based on a comparison between the trade statistics of source and destination countries at the tariffline level. In the absence of fraud, source and destination flows should be identical up to measurement errors and the difference between CIF and FOB valuations. Thus, the density function of the differences between the departure and arrival records should closely resemble a normal density centered around the CIF-FOB difference. Irregularities or 'thick tails' can reflect two economic forces, noted in the introduction: underinvoicing meant to avoid import duties, or overinvoicing meant to evade capital controls or local taxes.

In order to measure the extent of tariff evasion, we look at bilateral export flows from the EU to all countries having used PSI services, taking export values reported by EU customs shipments' true values (call it $V$ ) and import values reported by destination countries as underinvoiced values $(v)$. We then estimate, using the Kernel method, the weighted ${ }^{9}$ density function of the ratio $\omega \equiv(V-v) / V$ averaged over 5 years preceding and following the

\footnotetext{
${ }^{8}$ The 16 countries correspond to the number of countries for which we have trade data available before and after the introduction of PSI services. The econometric results in the next section are only give for 3 of these sixteen countries, for which we also had tariff data before and after the introduction of PSI services.

${ }^{9}$ Weighted by a measure of the volume of trade.
} 
introduction of PSI.

Figure 1 plots the difference between EU-Switzerland bilateral flows recorded by source and destination customs, in value. The density, while perhaps more easily approximated by a double exponential density than by a normal one, is indeed symmetric and regular.

By contrast, comparable densities for developing countries (three of which are reported in Figures 2-7) ${ }^{10}$ are highly irregular and suggest that more than measurement errors are at work. For those, evidence of underinvoicing largely dominates evidence of overinvoicing, as the distributions tend to be skewed to the right indicating that in a large number of transactions the value declared at the importing country is smaller than the value declared at the embarkation port. This is consistent with the fact that capital controls have largely been phased out.

In order to get a more precise estimate of the shift in underinvoicing frequencies, Table 1 shows the probability that the true value is larger than the declared import value before and after the introduction of the PSI in each of those three countries. It also shows the probability that the ratio $\omega$ takes a value in the right-hand tail $^{11}$ of the distribution, i.e. the likelihood of observing signficant levels of underinvoicing (both in terms of value and quantity).

A sharper test is based on the notion of first-order stochastic dominance. Consider two cumulative distribution functions $F^{1}$ and $F^{2}$, both defined on

\footnotetext{
${ }^{10}$ These are the three countries for which we also have tariff data before and after the introduction of PSI services and that we therefore use in our econometric analysis in the next section.

${ }^{11}$ Deviations higher than $80 \%$.
} 
R. $F^{1}$ is said to dominate $F^{2}$ in the first order if

$$
F^{1}(x)<F^{2}(x) \quad \forall x \in \mathbb{R} .
$$

The relationship between $F^{1}$ and $F^{2}$ and their respective densities $f^{1}$ and $f^{2}$ is shown in Figure 8. In Figure $1 F^{1}$ stochastically dominates $F^{2}$ in the first order, as it always lies below $F^{2}$, indicating that the probability of $x$ being larger than a certain number is always larger when the distribution takes the form of $f^{1}$.

Intuitively, first-order stochastic dominance describes a shift to the right of the density function such that the CDF's never cross. In our context, a shift to the right corresponds to more fraud. Therefore we can say that PSI is unambiguously successful if the pre-PSI distribution of $\omega$ dominates its post-PSI distribution in the first order. The test does not require any assumption about the relevant distributions (which the kernel technique does not characterize mathematically) but simply a plot of the relevant CDFs. By this test, the introduction of PSI was a success in six out of sixteen countries for which we have data available (Indonesia, Kenya, Mozambique, Niger, Senegal and Togo). It was a failure in two (Ecuador, and Madagascar); and the test is inconclusive for eight others (Argentina, Bolivia, Ghana, Guinee, Malawi, Mali, Peru and the Philippines). Figures 9-11 below show the kernel density and CDF estimates for three countries for which we will also report econometric results later on in this paper: Argentina, Indonesia, and the Philippines.

As mentioned above, and as can be seen from Figures 9-11, only Indonesia's CDFs represent an a priori clear-cut case in favour of PSI, since CDF 
curves before and after the introduction of PSI do not cross, and correspond to a displacement from the right (without PSI) to the left (with PSI). More interestingly, Indonesia's case is confirmed as an a priori success of PSI regardless of whether we choose the years preceding the introduction of PSI ${ }^{12}$ (1985) or those following the withdrawal of the program $^{13}$ (1997) to conduct the " with and without " analysis. In each case, the extent of fraud appears to be lower in the presence of PSI, an evidence which is both confirmed by the PSI company itself (SGS) and the recent complaints of the Indonesian private sector on customs behavior. Note that these results are robust to the type of trade data used, i.e. values or quantities. Yet whether this seemingly lower level of fraud is related to pure PSI effects still remain to be confirmed by a further theoretical approach and its proper econometric testing, enabling to disentangle between what is really due to PSI and what was the result of other factors.

As for Argentina, CDFs curves cross both at the lower and upper tails of the distribution, suggesting a worsening of extreme deviations cases in the presence of PSI. Since a conclusion cannot be drawn a priori in the Argentinian case, the evaluation of PSI efficiency for reducing fraud is entirely left to the approach which is developed in the next two sections. The Philippines CDFs do not provide an unambiguous answer either. Finally note that the CDFs curves, whether crossing or not, are rather close from each other,

\footnotetext{
${ }^{12}$ The years used to build the Kernel densities are then 1980, 1981, 1982, 1983 and 1984 for the " without PSI " density curve, and, 1985, 1986, 1987, 1988 and 1989 for the " with PSI " density curve.

${ }^{13}$ The years used to build the Kernel densities are then 1997, 1998, 1999, 2000 and 2001 for the " without PSI " density curve, and, 1992, 1993, 1994, 1995 and 1996 for the " with PSI " density curve.
} 
which The a priori suggests that the introduction of PSI had a weak impact on customs fraud.

The first-order dominance test, however, is both too strong and not enough. It is too strong in the sense that any crossing of the CDFs is enough to reject the hypothesis that fraud was reduced, even if this crossing is due to an irregularity in the density function (potentially itself the result of measurement errors). At the same time, it is not strong enough in that any arbitrarily small translation of the same distribution along the real axis qualifies as dominance. Therefore we turn now to a more formal approach.

\section{Underinvoicing: an analytical setup}

We explore the issues described above through a simple model featuring two components. First, a "positive" (i.e. descriptive) component sets out the strategic interaction between two classes of agents, importers and customs. The environment in which these agents make decisions (declared value for importers, inspection intensity for customs) is potentially affected by the presence and efficiency of a PSI company. Timing and information are specified precisely through the use of an extensive-form game. Second, a "normative" (i.e. policy choice) component features two types of control variables at the government's disposal: internal-incentive variables (bonuses to customs officers for fraud catches and sanctions for uncovered collusion with frauding importers) and external-incentive ones (intensity of use of PSI-provided information through reconciliation of customs and PSI data). The use of external (PSI-supplied) information acts as an incentive device provided that 
it is common knowledge, because it affects the effort and collusion decisions of customs through the probability of being caught. ${ }^{14}$ Both importers and customs are assumed purely opportunistic, which means that importers minimize tariff payments while customs maximize bribe and bonus income net of expected sanctions and the disutility of effort. Ethical considerations could be added easily to the objective function of customs but would add little to the analysis. ${ }^{15}$

We focus on a single transaction, for which the sequence of events is as follows. An importer chooses the declared value $v$ of a shipment worth $V$ on which a tariff is applicable at ad-valorem rate $t . \quad V$ is known only to the importer. ${ }^{16}$ At the port of embarkation, a PSI company inspects the shipment and reports its own estimate of shipment value in documentation sent to the destination port's customs, together with the importer's initial declaration. To fix ideas, think of the good being shipped as a piece of machinery whose valuation requires technical knowledge. With probability $p$, the PSI company possesses or acquires the required technical information and is able to value the shipment correctly at $V$. With probability $1-p$, it fails and simply reports the importer's declared value $v$. We will treat $p$, which can be thought of as the PSI company's reliability, as a parameter.

The next stage takes place at the destination port's customs where the shipment and accompanying documentation are inspected. ${ }^{17}$ Prior to inspec-

\footnotetext{
${ }^{14}$ We abstract from outright smuggling which entirely bypasses customs clearance and for which pre-shipment inspection provides no solution.

${ }^{15}$ This also implies that we have very little to say regarding the welfare of customs officers in different equilibrium.

${ }^{16}$ Focusing on a single transactions allows us to ignore shipment size issues, so $V$ can be thought of as either total or unit value.

${ }^{17}$ In principle, shipments subject to PSI are not liable to second inspection by destination
} 
tion, shipment value is considered by customs as a random variable $\widetilde{V}$. The (subjective) prior distribution of $\widetilde{V}$ does not need to be specified in what follows. Customs observe two signals on the basis of which they can update their prior: one from the importer and one from the PSI company. The pair of valuations provided in the two documents (importer declaration first, PSI document second) is either $(v, V)$ or $(v, v)$. In the former case, which occurs with probability $p,{ }^{18}$ customs obtain the correct valuation directly from the PSI company. In the latter, which occurs with probability $1-p$, they infer that the PSI company is simply reporting the importer's declaration which, in an interior equilibrium, they know to be wrong. ${ }^{19}$ In that case they undertake inspection. ${ }^{20}$ The surprising notion that customs undertake inspection only when PSI documents and importer declaration match comes from the fact that the importer's initial declaration to the PSI company is also sent to customs with the CRF or DR with no possibility for opportunistic revision. ${ }^{21}$

customs upon landing. Practices vary widely across countries, with 'second-inspection' rates ranging from $5 \%$ for some countries to $100 \%$ for others (e.g. Nigeria). There is no overall statistics on the rate of second inspection but a surveillance company estimates it at around $40 \%$ of shipments worldwide.

${ }^{18}$ As a simplification, we assume that $p$ is the PSI company's probability of finding the shipment's true value whether the importer declared truthfully or not. Letting the PSI company update its beliefs using $v$ would complicate the model's description without affecting its results.

${ }^{19}$ As will later become clearer, for some paramater values, it is possible to construct a "no-fraud" equilibrium assessment (set of strategies and beliefs) in which importers never fraud $(v=V)$ and customs beliefs are consistent with this. We will henceforth disregard this case, although it may of course occur in reality.

${ }^{20}$ Instead of being assumed, the situation in which customs do not perform second inspections at the destination port emerges endogenously as the equilibrium outcome when $p=1$ (see below).

${ }^{21}$ If it could be revised, then each time the PSI company followed the importer's initial declaration, the importer would underdeclare even further at customs in order to create the illusion that the PSI's higher valuation was the correct one. Customs' beliefs would therefore need to take account of this strategic behaviour. 
Let inspection intensity (effort) be measured by a continuous variable $e \in$ $[0,1]$ with quadratic effort cost $c(e)=e^{2} / 2$. Quadratic effort cost guarantees a closed-form solution. As in Aghion-Tirole, we will interpret $e$ both as a measure of customs effort and as the (endogenous) probability that the valuation obtained is correct. When the valuation is correct, customs know that it is so. The assumption is that the information can be readily verified.

Failing to produce the information, customs can only use $v$ as a signal to update their beliefs about shipment value. Even if they know, because the game's parameters are common knowledge, that importers always underinvoice in equilibrium, customs have in this case no verifiable information to support a fraud claim. In order to avoid introducing an element of arbitrariness in the model, we will then suppose that no fraud claim can be made, so that customs' beliefs are, in this particular instance, inconsequential.

Knowing customs' information set, the importer decides on a bribe offer $\beta$ expressed as a fraction of fraud value, which customs can accept or reject. Finally, the government reconciles through random audits the information provided by PSI and customs. Audit probability is $\pi$ and is a policy variable. ${ }^{22}$ Fraud, whether uncovered through audit or through customs reports, is met with a punitive tariff surcharge at ad-valorem rate T. Customs' "catches" are rewarded with a bonus $b$ expressed as a fraction of tariff revenue recovered, ${ }^{23}$ whereas cases of collusion between customs and frauding

\footnotetext{
${ }^{22}$ Reconciliation between PSI- and customs-provided information is very irregular. A surveillance company estimates the reconciliation ratio at around one third of all transactions subjected to PSI.

${ }^{23}$ In practice, rewarding customs officers with a percentage of catches is relatively uncommon. Incentive systems are however increasingly introduced as part of customs reform package and often include staff funds rather than individual rewards. There is no database
} 
importers are met with sanctions on customs officers. Those sanctions are assumed to have the form

$$
k=k_{0}+k_{1}(V-v) t
$$

i.e. including a constant and an amount proportional to the uncovered fraud. These two components are unlikely to be there simultaneously but their inclusion in the formulation makes it possible to explore two alternative interpretations: when $k_{1}=0$ the penalty is fixed (say, the officer is fired), whereas when $k_{0}=0$ the penalty is a fine or sanction (say, suspension without salary) proportional to the severity of the offense. The game is solved backwards.

\subsection{Equilibrium}

\subsubsection{Rent-sharing in collusive equilibria}

In the last stage of the game, customs, faced with a bribe offer $\beta$, decide to accept it or not. The information available to customs is a triplet $I=$ $\left(\nu_{I}, \nu_{P}, \nu_{C}\right)$ describing, in this order, the importer's declaration $\nu_{I}$, the PSI's valuation $\nu_{P}$, and customs' own valuation $\nu_{C}$. If any one of $I$ 's three elements is $V$, customs knows the shipment's true value with certainty and it knows that it knows. Let $x \in\{1,0\}$ be the customs' decision decision to accept the bribe or not, with the convention that $x=1$ means acceptance. Three cases must be considered.

Suppose first that the PSI company succeeds in valuing the shipment

comparing such incentive schemes but a customs analyst interviewed for this paper put the most common bonus rate at around $20 \%$ of the value of catches. 
correctly $\left(\nu_{P}=V\right)$. The state of information is $I_{P}=(v, V,$.$) . Knowing$ shipment value, customs considers inspection unnecessary and sets $e=0$. Accepting a bribe offer $\beta$ is risky because it could be uncovered through reconciliation of PSI and customs-provided documents; alternatively, reporting the discrepancy and charging the importer accordingly does not buy customs officers any bonus since the "catch" is really the surveillance firm's. ${ }^{24}$ Thus, customs' expected utility given the state of information is:

$$
u\left(x ; I_{P}\right)= \begin{cases}\left(\beta-\pi k_{1}\right)(V-v) t-\pi k_{0} & \text { if } x=1 \\ 0 & \text { if } x=0\end{cases}
$$

This defines the customs' participation constraint, i.e. the minimum bribe that customs can accept given the risk of detection. The importer sets $\beta$ so as to satisfy the constraint exactly, i.e. to leave customs just indifferent between accepting and not. The bribe is then always accepted, under the usual assumption that a binding participation constraint makes the contract acceptable. Solving and rearranging gives

$$
\beta_{P}=\pi k_{1}+\frac{\pi k_{0}}{(V-v) t}
$$

where the subscript means that $\beta_{P}$ is the bribe offered when the shipment's value has been reassessed by the PSI company.

Next, suppose that the PSI company does not correct the value of the shipment (i.e., issues a $\mathrm{CRF}$ ), reporting instead $\nu_{P}=v$. Then two cases arise, depending on whether customs is successful or not in its own valuation

\footnotetext{
${ }^{24}$ Adding a bonus when $x=0$ does not alter the results qualitatively.
} 
effort. If it is, the state of information is $I_{C}=(v, v, V)$. The importer offers again a bribe $\beta$, although at a different rate. Because PSI documents create no risk of 'hostile' reconciliation by the government, collusion is now risk-free for customs and

$$
u\left(x ; I_{C}\right)= \begin{cases}\beta(V-v) t & \text { if } x=1 \\ b(V-v) t & \text { if } x=0\end{cases}
$$

so the bribe offer is now $\beta_{C}=b .^{25}$

Finally, if customs is unsuccessful in its own valuation effort, the state of information is $I_{I}=(v, v, v)$; no credible threat of fraud claim can be made. Thus

$$
u\left(x ; I_{I}\right)= \begin{cases}\beta(V-v) t & \text { if } x=1 \\ 0 & \text { if } x=0\end{cases}
$$

which gives $\beta_{I}=0$ (no bribe).

\subsubsection{Customs Inspection intensity}

In our model, inspection takes place only when documentation provided by the PSI company is deemed uninformative by customs. In that case, ex ante, $V$ is a random variable $\widetilde{V}$ with expectation $E(\widetilde{V})$ and the inspection-intensity problem is:

$$
\max _{e} e \beta_{C}[E(\widetilde{V})-v] t-\frac{e^{2}}{2}=e b[E(\widetilde{V})-v] t-\frac{e^{2}}{2}
$$

\footnotetext{
${ }^{25}$ Thus, increasing the bonus for catching fraud increases the bargaining power of the customs officer when facing the bribing importer.
} 
which gives

$$
e(v)=b[E(\widetilde{V})-v] t
$$

Thus, equilibrium inspection intensity is increasing in the government-provided bonus $b$, in the tariff rate $t$, and in the level of fraud. Note that inspection is undertaken by customs only when the PSI valuations are considered uninformative because identical with importer-provided declarations. Thus, average inspection intensity is

$$
E[e(v)]=(1-p) b[E(\widetilde{V})-v] t
$$

which decreases with the efficiency of the PSI company. In other words, PSI efficiency is a strategic substitute for customs effort. Thus, the situation in which PSI operates smoothly at the embarkation port and customs never re-inspects at the destination port is the endogenous outcome of the model (rather than assumed) when $p=1$.

\subsubsection{Equilibrium declaration}

From now on, we will suppose that customs' (subjective) distribution for

$\widetilde{V}$ is centered on the shipment's true value, so $E(\widetilde{V})=V$, and that this is known to the importer (but not to customs itself). ${ }^{26}$ The importer's problem is to choose the declared value that minimizes the sum of duty payments and

\footnotetext{
${ }^{26}$ If customs knew what distribution $\widetilde{V}$ is drawn from and that this distribution is centered on $V$, they could infer $V$ and the information-production problem would disappear.
} 
expected penalties given equilibrium play in all subgames, that is,

$$
\begin{gathered}
\min _{v} p\left[\beta_{P}(V-v) t+(1-\pi) v t+\pi V(t+T)\right] \\
+(1-p)\left[v t+e \beta_{C}(V-v) t\right]
\end{gathered}
$$

s.t.

$$
\begin{aligned}
& \beta_{P}=\frac{\pi k}{(V-v) t}, \\
& \beta_{C}=b, \\
& e=b(V-v) t .
\end{aligned}
$$

The maximand has the following interpretation. Either the shipment's value is reassessed by the PSI company (an event with probability $p$ ) or not. If yes, upon arrival a bribe $\beta_{P}$ is paid to customs no matter what. If collusion with customs is uncovered by reconciliation (an event with probability $\pi$ ), the duty paid is $V(t+T)$ i.e. includes a penalty rate and is applied on the true value $V$. If not, duty paid is $v t$. If no reassessment, customs undertake inspection with intensity $e$. Duty is paid on the declared value $v$ no matter what. If inspection is successful (an event with probability $e$ ), in addition a bribe is paid at rate $\beta_{C}$.

Without the constraints, the importer's problem would always yield a corner solution since the cost function to be minimized is linear in $v$. Thus interior solutions (partial fraud) come from the importer's recognition that a low declared value triggers more careful inspection. ${ }^{27}$

\footnotetext{
${ }^{27} \mathrm{As} V$ is unkown, a lower $v$ triggers more careful inspection not because it is suspect, but because the expected return to inspection is an increasing function of $E(\widetilde{V})-v$ no matter what the distribution of $\widetilde{V}$ is.
} 
Let $\delta=V-v$ be the degree of fraud. Expressed in terms of $\delta$, the first order condition is:

$$
\delta=\frac{1}{2 b^{2} t}\left[\frac{1-\pi p\left(1+k_{1}\right)}{1-p}\right] .
$$

It is easily verified that the game without PSI is outcome-equivalent to a game with PSI but with $p=0$. Letting

$$
\alpha \equiv \frac{1-\pi p\left(1+k_{1}\right)}{1-p},
$$

we have thus

$$
\delta= \begin{cases}\alpha / 2 b^{2} t & \text { with PSI } \\ 1 / 2 b^{2} t & \text { without. }\end{cases}
$$

We have refrained from using Kuhn-Tucker conditions for ease of notation but it should be clear that corner solutions can be obtained at $\delta=V$ (total fraud, which can be thought of as smuggling) when $\alpha$ is large enough, or at $\delta=0$ when $\alpha<0$. In the latter case fraud is entirely eliminated by the introduction of PSI. Two points are worth noting. First, unlike what has often been suggested (Goorman and De Wulf, 2003 and Low, 1995), perfect reconciliation (i.e., $\pi=1$ does not necessarily lead to the elimination of customs fraud $(\delta=0)$ if the PSI company is not very efficient $(p<<1)$ (and the proportional part of the penalty is not very large, i.e., $k_{1} \approx 0$ ). A fuller discussion of the effect of introducing PSI is differed until the next section. 


\subsection{Comparative statics}

The model generates both positive and normative results which can be derived as comparative-statics properties. As for positive results, the first and most surprisingly is that fraud declines with the tariff for a wide range of parameter values. This surprising result, which stands in contrast with the findings of Fisman and Wei (2001), is due to the strategic interaction between importer and customs. With collusive rent-sharing, a higher tariff raises customs' incentive to find verifiable evidence of fraud, since such evidence improves customs' bargaining position (more exactly its participation constraint). This strategic effect reduces the importer's fraud rent and swamps the direct effect that a higher tariff exerts on the return to fraud, reducing its equilibrium level. ${ }^{28}$ Because the inverse relationship between $\delta$ and $t$ is somewhat counterintuitive, it provides a test of the model's validity as a descriptive tool.

As for normative results, raising the power of incentives facing customs through an increase in the bonus rate $b$ reduces the equilibrium level of fraud, an intuitive result since fraud is encouraged by collusion with customs. So does raising the frequency of audits $(\pi)$ and the rate of sanctions.

By (6), the introduction of PSI reduces the degree of fraud if and only if $\alpha<1$, i.e. if $\pi\left(1+k_{1}\right)>1$. The model highlights the interdependence of PSI

\footnotetext{
${ }^{28}$ That the indirect effects (through customs' effort) always swamps the direct effect (through fraud revenue) may seem surprising, but recall that without the indirect effect the problem admits only corner solutions because the importer's minimand is linear in $t$. The fact that fraud is observed and is less than one hundred percent suggests, in this model's logic, that the desire to avoid attracting customs attention through gross underinvoicing is indeed a key consideration (in accordance with intuition). The inverse relationship with $t$ then follows directly from the algebra.
} 
efficiency $(p)$ and reconciliation rates $(\pi)$ in curbing fraud. Differentiating (5) with respect to $p$ at the two extreme values of $\pi$ gives

$$
\frac{\partial \alpha}{\partial p}=\frac{1-\pi\left(1+k_{1}\right)}{(1-p)^{2}}=\left\{\begin{array}{cc}
-k_{1} /(1-p)^{2} & \text { if } \pi=1 \\
1 /(1-p)^{2} & \text { if } \pi=0
\end{array}\right.
$$

It can be shown that there is a single point where $\partial \alpha / \partial p$ changes sign. Thus, more efficient PSI (a higher $p$ ) reduces fraud only when the rate of reconciliation $(\pi)$ is high enough. When $\pi=p=1, \alpha$ is negative and a corner solution is obtained at $\delta=0$ (no fraud). It can be also seen that when $\pi$ is high enough to make $\partial \alpha / \partial p$ negative (upper part of 7) the latter goes up in absolute value with increases in $k_{1}$, the rate of sanctions on customs officers. This set of results highlights the complementarity of PSI with government efforts to fight customs corruption through internal incentives $\left(k_{1}\right)$ and to make use of PSI information $(\pi)$.

The intuition of the case in which the introduction of PSI ends up raising fraud is as follows. When fraud is uncovered through PSI (case $I_{P}$ ) the bargaining position of corrupt customs is weak due to the fact that reporting the fraud brings no bonus. Therefore the informational rent generated by PSI is entirely captured by the importer, which raises the return to fraud. There is then more fraud in equilibrium. Introducing a bonus for when customs officers report fraud uncovered by PSI or letting the rent be shared by the Nash bargaining solution would weaken this mechanism but would not necessarily reverse it. ${ }^{29}$ Thus, in general whether PSI reduces tariff evasion is an empirical question.

\footnotetext{
${ }^{29}$ For instance, introducing a bonus at rate $b_{1}$ for customs officers using PSI data to
} 
In models of information production in which efforts are strategic substitutes, the arrival of an additional information-producing agent can either raise or lower aggregate information production, depending on whether the agent's direct contribution to aggregate effort offsets or not the negative effect of her arrival on the marginal effort of other agents. Here, customs effort is indeed decreasing in the PSI company's efficiency, as $E(e)$ is a decreasing function of $p$ (see (3)). However aggregate information production necessarily goes up with the introduction of PSI. To see this, define $\phi$ to be the probability that the shipment's true value is established by either customs or the PSI firm. With PSI,

$$
\begin{aligned}
\phi & =p+e(1-p) \\
& =p+(1-p) b(V-v) t
\end{aligned}
$$

using (2). Without PSI, customs' effort is still given by (2), so

$$
\widetilde{\phi}=b(V-v) t
$$

report fraud would change (7) into

$$
\frac{\partial \alpha}{\partial p}=\frac{1-\left[b_{1}+\pi\left(1+k_{1}\right)\right]}{(1-p)^{2}}=\left\{\begin{array}{cc}
-\left(b_{1}+k_{1}\right) /(1-p)^{2} & \text { if } \pi=1 \\
\left(1-b_{1}\right) /(1-p)^{2} & \text { if } \pi=0 .
\end{array}\right.
$$

Obviously, qualitative results would not change as long as the bonus rate is less than one (which it realistically has to be), but increases in $p$ would have a stronger effect when $\pi$ is high enough. 
It is easily seen that

$$
\begin{aligned}
\phi-\widetilde{\phi} & =p[1-b(V-v) t] \\
& =p[1-e(v)]>0
\end{aligned}
$$

where the last inequality follows from the fact that $e$ is a probability. The reason for this result is that information production is here sequential instead of simultaneous, as it is in Aghion-Tirole or Anson. Once PSI has been observed to fail, customs face essentially the same problem that they would without PSI, so they do not free-ride on PSI effort. This means that information-production efforts are additive.

In sum, the introduction of PSI unambiguously improves the state of information. However, its effect on fraud is only indirect, and the model's answer to the question 'does PSI help?' is reflected in the slope difference between the upper and lower parts of (6). We now turn to an empirical test of the model's predictions.

\section{$5 \quad$ Econometric estimation}

This section presents an attempt to estimate structurally first-order condition (6) on panels of imports from the EU, disaggregated at the SITC2 5 digit level for PSI-using countries. The initial sample included 52 countries. Of those, 16 had disaggregated trade data for a sufficient number of years before the introduction of a PSI program and a sufficient number of years after. Among those 16, 6 had tariff data as well, but only 3 for years preceding and following the introduction of PSI (i.e. Argentina, Philippines and Indonesia). 
Thus, the final sample has 3 countries, each with between 5,799 and 7,019 observations (tariff lines at the SITC 5 digit level). Trade data is from the UN's Comtrade database and tariff data from UNCTAD's Trains.

\subsection{Procedure}

The equation to be tested is a stochastic version of equation (6) estimated by country after pooling pre- and post-PSI years respectively. As heteroskedasticity is likely to be an issue, Eicker-White heteroskedasticity consistent estimators are provided. We will thus be able, without specifying the type of heteroskedasticity, to make valid inferences based on the results of ordinary least squares. In order to avoid having $V$ on both the RHS and LHS, we rewrite (6) as

$$
v(V, t)= \begin{cases}V-\alpha / 2 b^{2} t & \text { with PSI, } \\ V-1 / 2 b^{2} t & \text { without. }\end{cases}
$$

Although the model has no constant, we add time effects to pick up the influence of out-of-model changes in the environment. The effect of tariff changes and customs reforms involving changes in incentive structures should be picked up by parameter estimates, but other changes in the environment need to be controlled for.

In order to account for positive deviations of $v$ from $V$ (those are aberrations in the model but nevertheless present in the sample) we interact $1 / t$ with a dummy variable $z$ equal to one when $v<V$ (the normal case). Although several approaches are possible to deal with this problem, none yielded drastically different results and we view this one as a better alternative than dropping altogether the "problem" lines, which would bias the 
sample. ${ }^{30}$ Finally, the dummy variable $\tau$ is equal to one in PSI years and zero otherwise. PSI years are 1998-2000 for Argentina, 1993-1995 and 1998-2000 for the Philippines, and 1989-90, 1993, 1995-6 for Indonesia. The holes in PSI years for Indonesia and the Philippines are years without tariff data.

Letting subscripts $i$ and $k$ refer respectively to periods and commodities, the transformed structural equation to be estimated is:

$$
v_{i k}=\sum_{i=1}^{T} \beta_{0 i} d_{i}+\beta_{1} V_{i k}+\beta_{2} \frac{z_{i k} \tau_{i}}{t_{i k}}+\beta_{3} \frac{z_{i k}\left(1-\tau_{i}\right)}{t_{i k}}+\varepsilon_{i k}
$$

where $\varepsilon_{i k}$ is an error term. Note that source custom values are FOB whereas destination values are CIF, so in order to interpret the former as true values and the latter as 'underinvoiced' values, the CIF/FOB difference must be taken into account.

The model's predictions are $\beta_{1}=\theta>1$, where $\theta$ is the $\mathrm{CIF} / \mathrm{FOB}$ ratio, $\beta_{2}=-\alpha / 2 b^{2}<0$, and $\beta_{3}=-1 / 2 b^{2}<0$. Some of the model's structural parameters can be retrieved from the estimates. For instance, $b=\sqrt{1 / 2 \beta_{3}}$ and $\alpha=\beta_{2} / \beta_{3}$. Using an interview-provided "guesstimate" of $\pi$ equal to 0.3 (see supra), the implied estimates for $\alpha$ and $b$ can be used to get one for $p$ under different hypotheses for $k_{1}$.

\subsection{Results}

Robust regression results are shown for Argentina, the Philippines and Indonesia (with numbers of observations ranging between 5,799 and 7,019 for

\footnotetext{
${ }^{30}$ Our method implies that the influence of observations with $v>V$ is picked up by the constants (year effects) and the error term, which is appropriate if those observations are thought of as measurement errors.
} 
each regression) in Table 2. As predicted by the model, for all countries the coefficient on $1 / t_{i k}$ is negative ${ }^{31}$ (recall that the dependent variable is $v$ rather than the degree of fraud) and always significant at the $1 \%$ level. $\widehat{\beta}_{2}$ ranges across regressions between $-25,076$ (for Argentina) and -10,752 (for Indonesia); $\widehat{\beta}_{3}$ ranges between $-15,824$ (Philippines) and -8, 218 (Argentina).

One of the model's implications is that PSI reduces fraud when $\alpha$ is smaller than one. As $\widehat{\alpha}=\widehat{\beta}_{2} / \widehat{\beta}_{3}$, we have

$$
\widehat{\alpha}= \begin{cases}3.051 & \text { for Argentina, } \\ 0.585 & \text { for the Philippines, } \\ 1.257 & \text { for Indonesia. }\end{cases}
$$

Thus, the point estimates suggests that customs fraud has increases with the introduction of PSI services in Argentina and Indonesia. Testing the null hypothesis that $\widehat{\alpha}=1$ (no effect for PSI) gives Wald test statistics of $F(1,5893)=56.74$ for Argentina, $F(1,7006)=7.28$ for the Philippines, and $F(1,5789)=1.02$ for Indonesia. The null hypothesis is accepted for Indonesia, for which PSI appears to have had no traceable effect, but rejected for the other two countries. In the Philippines, PSI helped, whereas in Argentina, it seems to have made things worse. ${ }^{32}$

Implied estimates of $b$ (the bonus rate for catches, a proxy for inter-

\footnotetext{
${ }^{31}$ We also estimated the model by country and year, and got a significant negative coefficient on $1 / t_{k}$ in 47 regressions out of 49 .

${ }^{32}$ Note that our estimation does not control for evasion of customs tariffs through the more intese use of duty free zones, which Yang (2003) suggest were an importance force in evading customs tariffs in the Phillipines after the introduction of PSI services. Taking this account may weakened even further the case for PSI services.
} 
nal incentives in customs administrations) are $\widehat{b}=0.00780$ for Argentina, $\widehat{b}=0.00562$ for the Philippines and $\widehat{b}=0.00765$ for Indonesia, suggesting very weak incentives. These low estimates are in accordance with anecdotal evidence. Substituting estimated values for $b$ and using $\pi=0.3$ gives estimates of $p$ (the frequency of catches by PSI firms) depending on $k_{1}$. For Argentina, for instance, we get $\widehat{p}(0)=0.745$ and $\lim _{k_{1} \rightarrow \infty} \widehat{p}=1$. For the Philippines, we get $\widehat{p}(2.3)=1$ and $\lim _{k_{1} \rightarrow \infty} \widehat{p}=0\left(k_{1}\right.$ cannot be lower than 2.3 when $\alpha$ is less than one). The fact that implied estimates of $p$ are between zero and one is consistent with the model where $p$ is a probability.

Finally, $\widehat{\beta}_{1}$ provides an estimate of $\mathrm{CIF} / \mathrm{FOB}$ ratios equal to 0.987 for Argentina, 1.329 for the Philippines and 1.150 for Indonesia. The estimate for Argentina is clearly biased downward, but the upper bound of the $95 \%$ confidence interval (equal to 1.03675) is nevertheless above unity. The other two estimates are plausible. In sum, most estimates of the model's parameters, direct or implied, are in plausible ranges, vindicating the approach taken in section 4 .

\section{Concluding Remarks}

This paper attacked the title's question ('does PSI help reducing tariff evasion?') from two perspectives. First, we showed prima-facie evidence based on non-parametric methods suggesting a mixed picture, with some cases of unambiguous reductions in evasion and others suggesting no improvement. The problem with this approach is that it does not control for other tariff and customs reforms that may have occurred simultaneously when trying to 
evaluate the impact of the introduction of PSI services in client countries.

The second approach corrects for this and uses a structural model. We derived a simple game-theoretic setup with strategic interaction between importers' fraud decisions and customs' effort. The model has positive and normative implications. It highlights that importers understand that customs have a sharper eye on high-rate tariff lines, making fraud trickier (if potentially more lucrative) in those lines. Denunciation fears act only as off-equilibrium threats, the equilibrium being generally one with collusion between frauders and corrupt customs. Based on relatively straightforward strategic interaction, the model predicts less fraud in tariff lines with high rates (because those are the ones on which customs focus their attention). This counterintuitive prediction provides a test of the model against the traditional, intuitive approach that higher tariff rates encourage fraud. Perhaps more importantly, the model suggests that PSI's impact on the extent of fraud is theoretically ambiguous. The reason is, intuitively, that PSI produces information which is only worth what the client government authorities decide to do with it. PSI may even have a perverse effect in de'-motivating' customs. This effect appears indirectly in our model through the following mechanism. When reporting fraud uncovered by PSI, customs officers do not expect to receive bonuses (as opposed to when they uncover fraud themselves). Their only motivation to report PSI data and force importers to pay penalty duties is the threat of sanctions if data is later reconciled. When the frequency of reconciliation is low (as it typically is) that incentive is weak. This, in turn, creates a situation where collusion between frauding importers and customs is likely. At the same time, the weakness of customs' incen- 
tive to report affects out-of-equilibrium payoffs in a way that strengthens the bargaining position of importers, raising the equilibrium return to fraud and, consequently, the incentive to fraud. If the chain of incentive effects just described may seem somewhat indirect, its final outcome (demobilized customs) has been widely observed in countries adopting PSI (Low, 1995 and Goorman and De Wulf, 2003).

Finally, we tested the model on panels of imports between the EU and PSI-using countries at a high degree of disaggregation and found that its basic prediction (fraud being inversely related to tariff rates) was strongly supported by the data. Structural parameter estimates are in plausible ranges, giving support to our modeling approach. Finally, econometric results for the three countries for which we have tariff and trade data before and after PSI suggest that the introduction of PSI in those countries led to an increase in the extent of fraud in Argentina, lending support to the model's claim that indirect (incentive) effects can dominate direct (information-production) effects, and was clearly successful only in the Philippines. Indonesia appears as a mixed case.

\section{References}

[1] Aghion, Philippe, and Jean Tirole (1997), "Formal and Real Authority in Organizations"; Journal of Political Economy 105, 1-29.

[2] Anson, Jose (2003), "Costly Information Acquisition and the Power of Lobbies"; mimeo, University of Lausanne. 
[3] Byrne, Peter (1995), "An Overview of Privatization in the Area of Tax Administration"; Bulletin for International Fiscal Documentation 49, $10-16$.

[4] De Wulf, Luc (1981), "Statistical Analysis of Under- and Overinvoicing of Imports", Journal of Public Economics 8, 303-323.

[5] Dutz, Mark (1996), "Observations on the Use and Usefulness of PresShipment Inspection Services"; mimeo, The World Bank.

[6] Feenstra, Robert, and Gordon Hanson (2000), "Aggregation Bias in the Factor Content of Trade: Evidence from US Manufacturing", American Economic Review 90, 155-160.

[7] Fisman, Raymond, and Shang-Jin Wei (2001), "Tax Rates and Tax Evasion: Evidence from 'Missing Imports' in China"; NBER working paper 8551 .

[8] Fundacion Investigaciones Economicas Latinoamericanas (1999), "Customs Control in an Open Economy: The Case of the Preshipment Inspection Program in Argentina"; mimeo.

[9] Gatti, Roberta (1999), "Corruption and trade tariffs or a case for uniform tariffs", Policy Research Working Papers \# 2216.

[10] Goorman, Adrien and Luc De Wulf (2003), "Customs valuations under the new WTO rules: problems and possible measures with particular attention for developing countries", mimeo, The World Bank. 
[11] Johnson, Noel (2001) "Committing to Civil Service Reform: The Performance of Pre-Shipment Inspection under Different Institutional Regimes"; mimeo, Washington University at St Louis.

[12] Low, Patrick (1995), "Preshipment Inspection Services", World Bank Discussion Paper 278..

[13] Medalla, Erlinga, L.C. de Dios and R. Aldaba (1003), "Effects of HCV Valuation: A Policy Paper"; PhilExport/USAID.

[14] — and Leah Panganiban-Castro (1999), "The Effects of Shifting to Transaction Value and Other Issues"; Final Report, PhilExport/USAID.

[15] Ramirez Acuna, Luis (1992), "Privatization of Tax Administration", in Bird and Casanegra, eds., Improving Tax Administration in Developing Countries.

[16] Slemrod, Joel, and Shlomo Yitzhaki (2000), "Tax Avoidance, Evasion, and Administration"; NBER working paper 7473.

[17] Stella, Peter (1993), "Tax Farming: A Radical Solution for Developing Country Tax Problems?", IMF Staff Papers 40.

[18] WTO (1999) Examen des Politiques Commerciales: Republique de Guinee; Geneva: WTO.

[19] Yang, Dean (2003), "How Easily do Lawbreakers Adapt to Increased Enforcement? Philippine Smugglers Responses to a Common Customs Reform"; mimeo, Harvard. 
Table 1: Tariff evasion before and after PSI

\begin{tabular}{|l|c|c|c|c|}
\hline Country & \multicolumn{2}{|c|}{ Values } & \multicolumn{2}{c|}{ Quantities } \\
\hline & $\operatorname{Pr}(\delta>0)$ & $\operatorname{Pr}(\delta>0.8)$ & $\operatorname{Pr}(\delta>0)$ & $\operatorname{Pr}(\delta>0.8)$ \\
\hline Indonesia & $(.55, .63)$ & $(.10, .17)$ & $(.58, .61)$ & $(.08, .14)$ \\
\hline Philippines & $(.69, .68)$ & $(.15, .10)$ & $(.57, .62)$ & $(.13, .09)$ \\
\hline Argentina & $(.62, .51)$ & $(.03, .03)$ & $(.71, .61)$ & $(.04, .07)$ \\
\hline
\end{tabular}

Note: Values reported in parentheses: without PSI first, with PSI second. 
Table 2: Estimation Results

\begin{tabular}{|c|c|c|c|}
\hline Variable & Argentina & Philippines & Indonesia \\
\hline$V_{i k}$ & $\begin{array}{c}0.987^{* * *} \\
(0.026)\end{array}$ & $\begin{array}{c}1.329^{* * *} \\
(0.197)\end{array}$ & $\begin{array}{c}1.150^{* * *} \\
(0.099)\end{array}$ \\
\hline$\left(z_{i k} \tau_{i}\right) / t_{i k}$ & $\begin{array}{c}-25076.45^{* * *} \\
(1791.95)\end{array}$ & $\begin{array}{c}-9260.48^{* * *} \\
(2137.09)\end{array}$ & $\begin{array}{c}-10752.15^{* * *} \\
(1720.86)\end{array}$ \\
\hline$\left(z_{i k}\left(1-\tau_{i}\right)\right) / t_{i k}$ & $\begin{array}{c}-8218.49^{* * *} \\
(1348.83) \\
\end{array}$ & $\begin{array}{c}-15823.84^{* * *} \\
(2173.71)\end{array}$ & $\begin{array}{c}-8553.79^{* * *} \\
(1613.14) \\
\end{array}$ \\
\hline$d_{1988}$ & & $\begin{array}{c}332.75^{*} \\
(191.18) \\
\end{array}$ & \\
\hline$d_{1989}$ & & $\begin{array}{l}180.70 \\
(191.60) \\
\end{array}$ & $\begin{array}{c}775.36^{* * *} \\
(170.04)\end{array}$ \\
\hline$d_{1990}$ & & $\begin{array}{c}650.28^{* *} \\
(270.19)\end{array}$ & $\begin{array}{c}690.50^{* * *} \\
(238.19)\end{array}$ \\
\hline \multicolumn{4}{|l|}{$d_{1991}$} \\
\hline$d_{1992}$ & & $\begin{array}{l}103.24 \\
(244.33)\end{array}$ & \\
\hline$d_{1993}$ & & $\begin{array}{c}-89.60 \\
(198.28)\end{array}$ & $\begin{array}{c}1469.34^{* * * *} \\
(354.06)\end{array}$ \\
\hline$d_{1994}$ & & $\begin{array}{r}297.05 \\
(241.22)\end{array}$ & \\
\hline$d_{1995}$ & $\begin{array}{c}593.02^{* * *} \\
(134.71) \\
\end{array}$ & $\begin{array}{l}198.68 \\
(283.99) \\
\end{array}$ & $\begin{array}{c}907.71^{* * *} \\
(329.27) \\
\end{array}$ \\
\hline$d_{1996}$ & $\begin{array}{c}563.64^{* * *} \\
(151.09)\end{array}$ & & $\begin{array}{c}1240.62^{* * *} \\
(306.21)\end{array}$ \\
\hline$d_{1997}$ & $\begin{array}{c}808.95^{* * *} \\
(170.37)\end{array}$ & & \\
\hline$d_{1998}$ & $\begin{array}{c}1640.14^{* * *} \\
(173.02)\end{array}$ & $\begin{array}{c}869.10^{* *} \\
(337.13)\end{array}$ & \\
\hline$d_{1999}$ & $\begin{array}{c}1658.94^{* * *} \\
(151.59)\end{array}$ & $\begin{array}{c}1148.22^{* *} \\
(471.20)\end{array}$ & $\begin{array}{c}818.70^{* * *} \\
(218.19)\end{array}$ \\
\hline$d_{2000}$ & $\begin{array}{c}1503.14^{* * *} \\
(131.18) \\
\end{array}$ & $\begin{array}{c}1125.06^{*} \\
(611.32) \\
\end{array}$ & $\begin{array}{c}645.19^{* * *} \\
(204.20) \\
\end{array}$ \\
\hline Number of observations & 5902 & 7019 & 5799 \\
\hline Adjusted $R^{2}$ & 0.8716 & 0.2984 & 0.7027 \\
\hline F-Stat & 646.88 & 103.06 & 282.05 \\
\hline
\end{tabular}

Note: standard error of coefficient between parenthesis 
Figure 1: Switzerland's Kernel Density

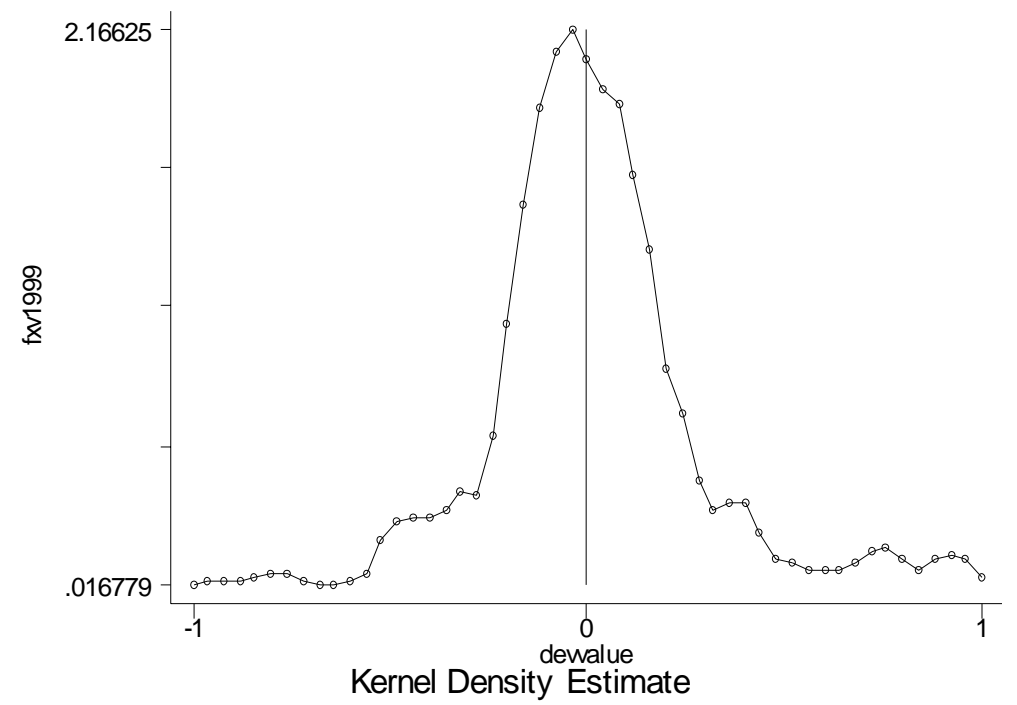


Figure 2: Kernel Density For Value Deviations (Argentina)

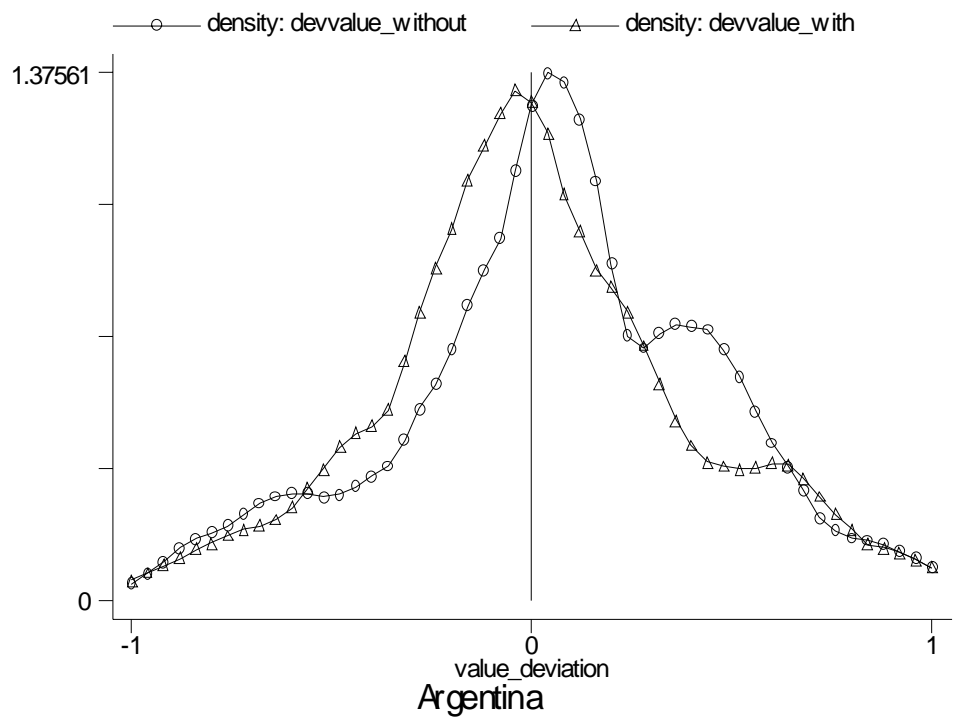

Figure 3: Kernel Density For Quantity Deviations (Argentina)

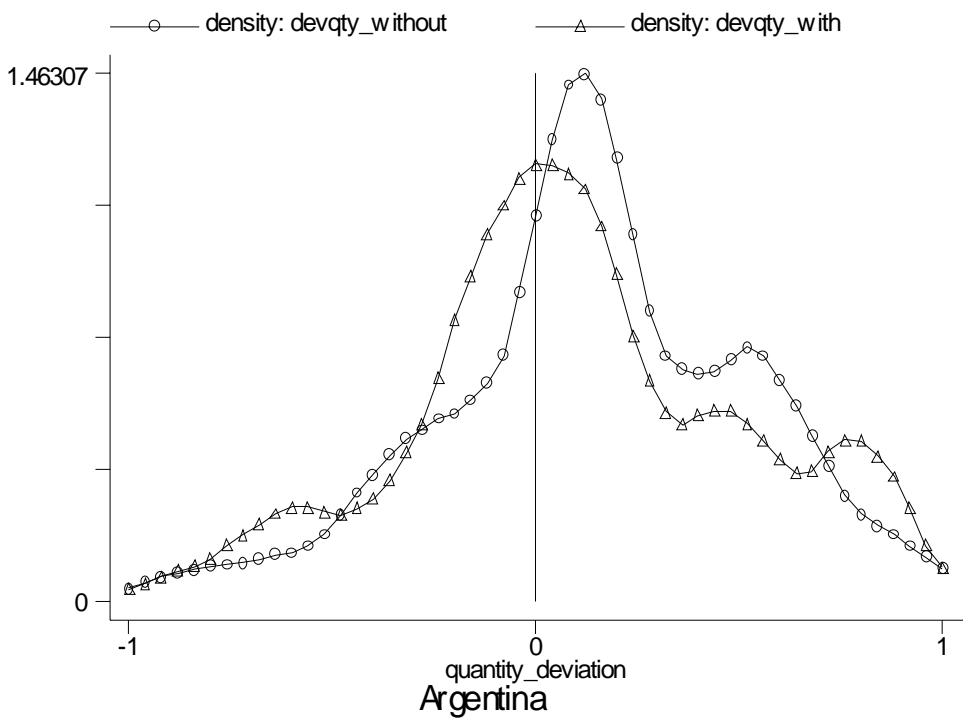


Figure 4: Kernel Density for Value Deviations (Philippines)

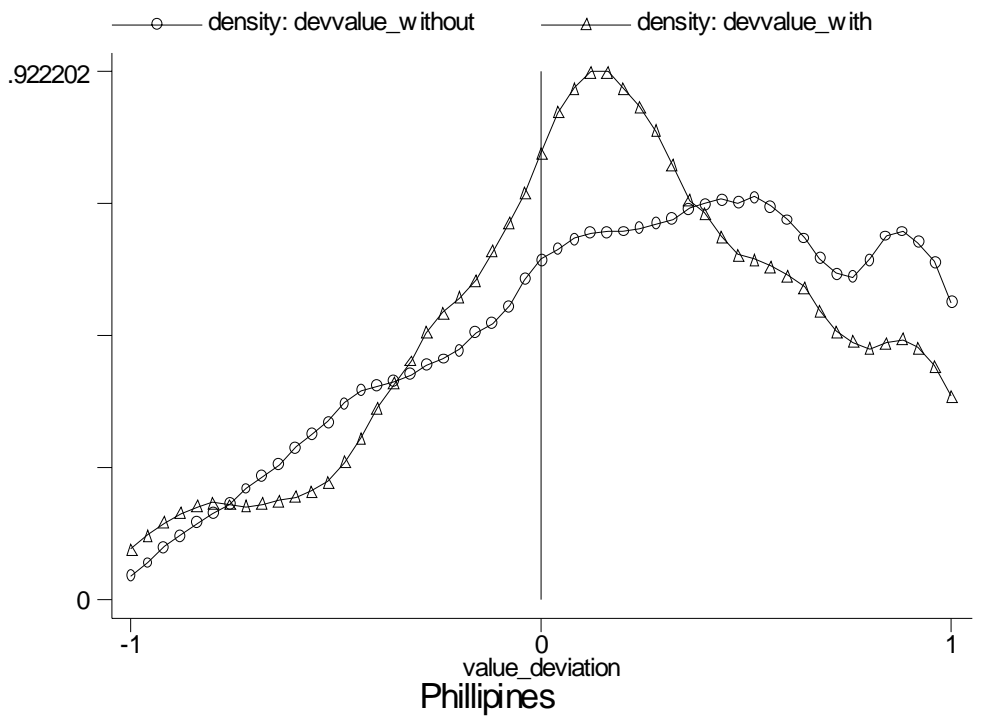

Figure 5: Kernel Density For Quantity Deviations (Philippines)

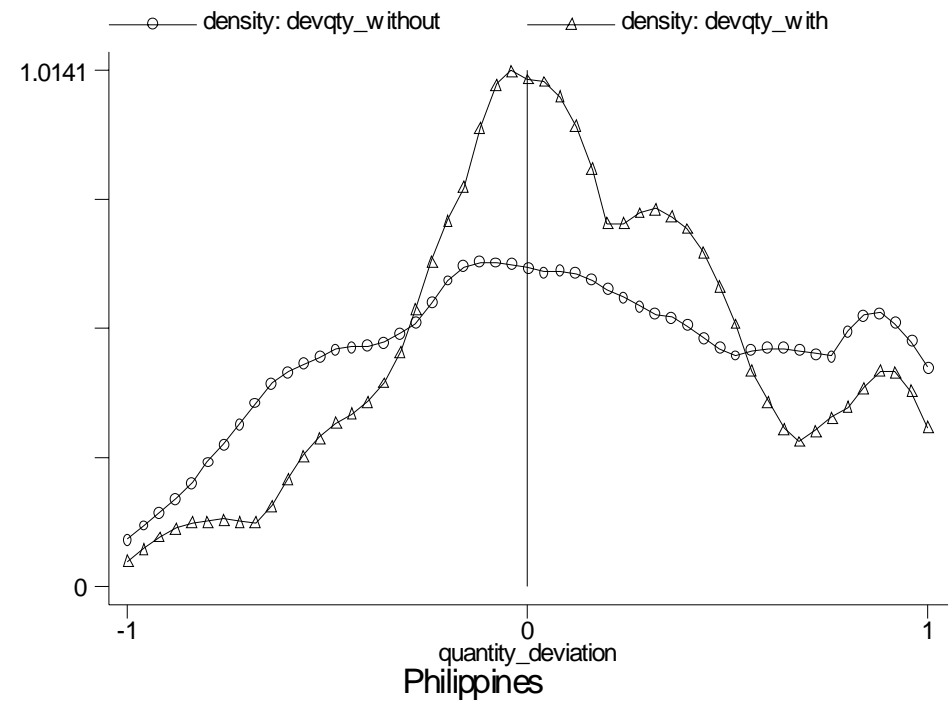


Figure 6: Kernel Density for Value Deviations (Indonesia)

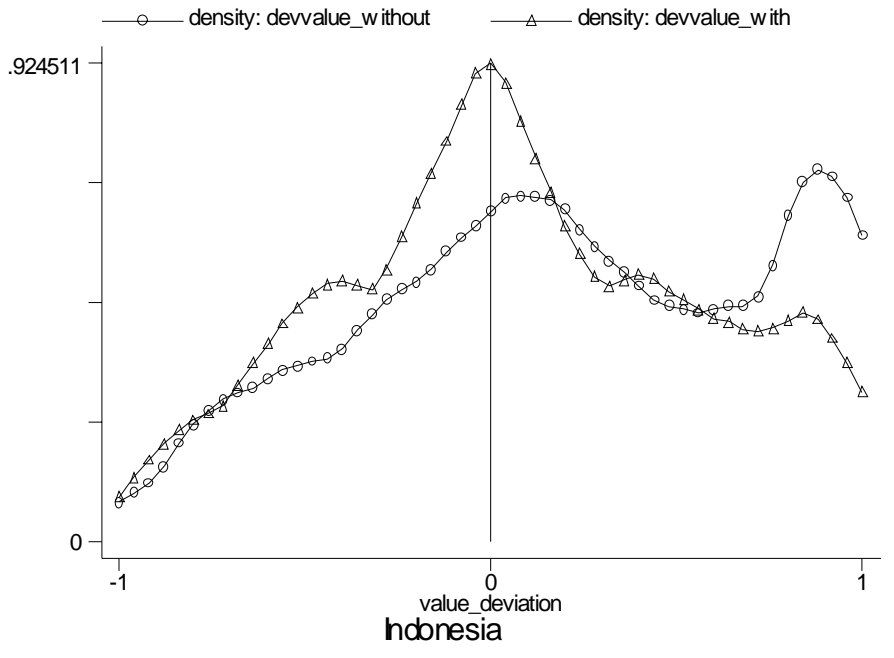

Figure 7: Kernel Density For Quantity Deviations (Indonesia)

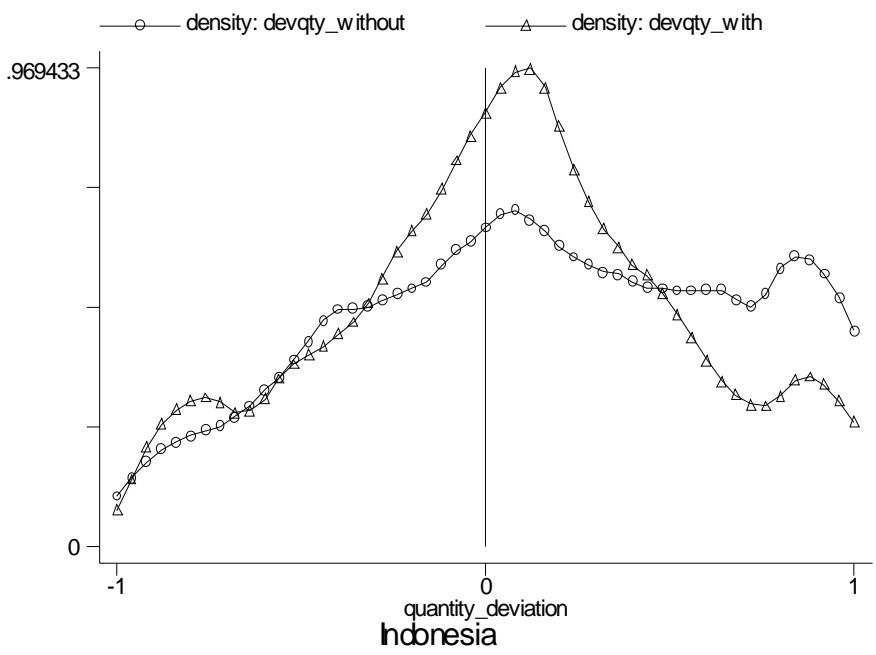


Figure 8: First Order Stochastic Dominance

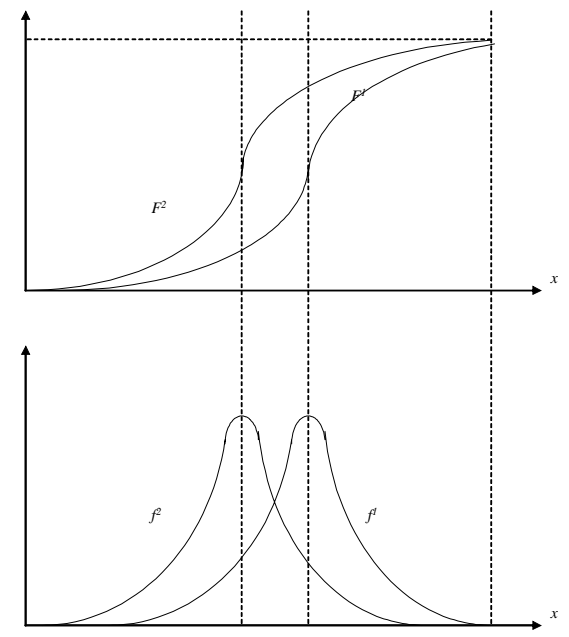

Figure 9: CDFs for Argentina (values)

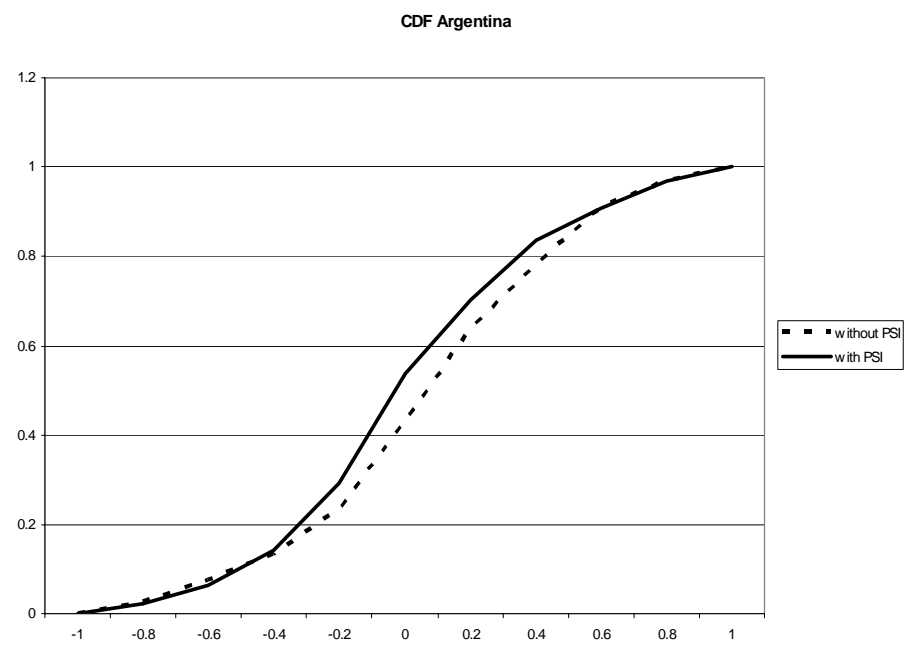


Figure 10: CDFs for the Philippines (values)

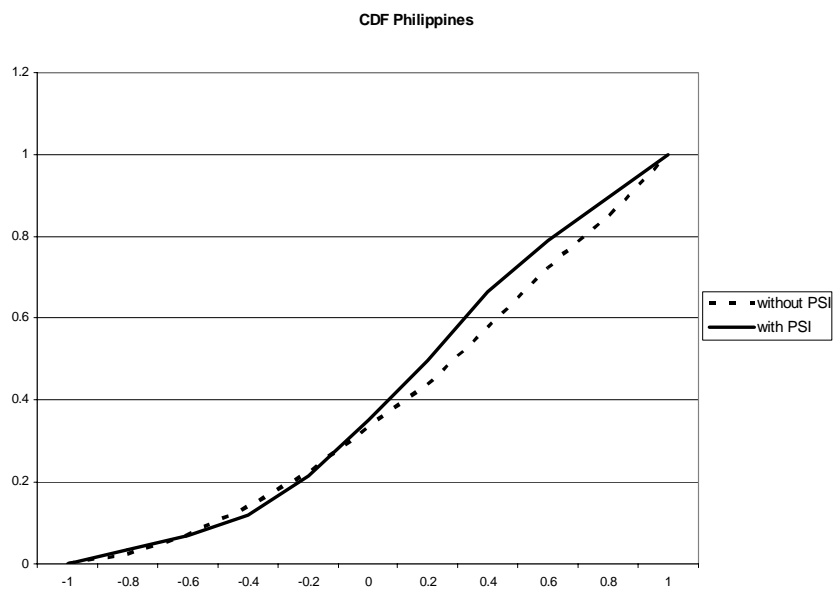

Figure 11: CDFs for Indonesia (values)

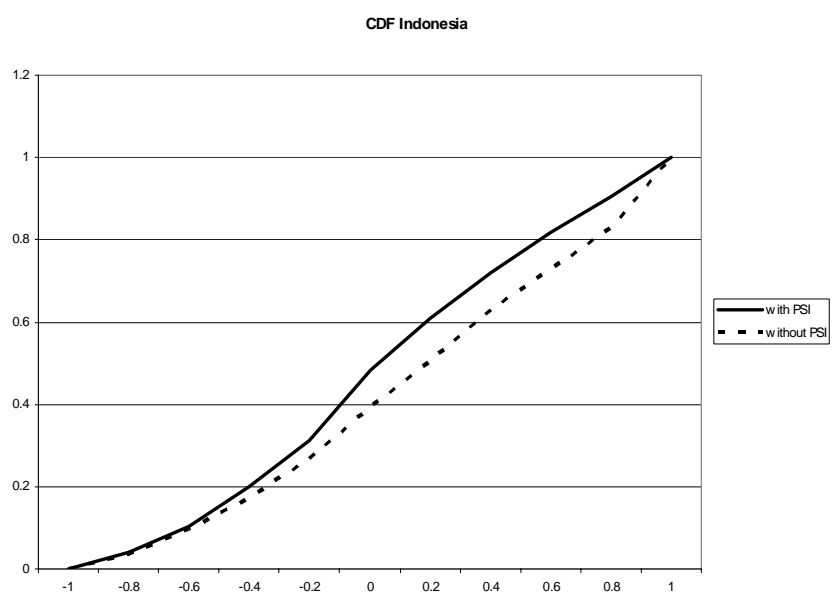

